\title{
Addressing obsolescence of consumer electronics through sustainable interaction design
}

\author{
Remy, Christian
}

\begin{abstract}
The obsolescence of consumer electronics is a major topic in the domain of sustainable HCI, which has seen a variety of theoretical frameworks emerging to address this issue. My research seeks to apply one of those established theoretical frameworks from sustainable HCI research, the Attachment Framework, to design practice. The goal of my research is to identify opportunities and challenges in bringing theoretical frameworks from sustainable HCI research to practitioners outside of our field, ultimately creating guidelines and scenarios that aid in overcoming the problem of obsolete consumer electronics.
\end{abstract}

DOI: https://doi.org/10.1145/2702613.2702621

Posted at the Zurich Open Repository and Archive, University of Zurich

ZORA URL: https://doi.org/10.5167/uzh-110998

Conference or Workshop Item

Published Version

Originally published at:

Remy, Christian (2015). Addressing obsolescence of consumer electronics through sustainable interaction design. In: CHI'15: Extended Abstracts of the thirty-third annual SIGCHI conference on Human factors in computing systems, Seoul, Korea, 18 April 2015 - 23 April 2015. ACM, 227-230.

DOI: https://doi.org/10.1145/2702613.2702621 


\section{Addressing Obsolescence of Consumer Electronics through Sustainable Interaction Design}

\author{
Christian Remy \\ University of Zürich \\ Binzmühlestrasse 14 \\ 8050 Zürich, Switzerland \\ remy@ifi.uzh.ch
}

\begin{abstract}
The obsolescence of consumer electronics is a major topic in the domain of sustainable $\mathrm{HCI}$, which has seen a variety of theoretical frameworks emerging to address this issue. My research seeks to apply one of those established theoretical frameworks from sustainable HCI research, the Attachment Framework, to design practice. The goal of my research is to identify opportunities and challenges in bringing theoretical frameworks from sustainable HCI research to practitioners outside of our field, ultimately creating guidelines and scenarios that aid in overcoming the problem of obsolete consumer electronics.
\end{abstract}

\section{Author Keywords}

Sustainable HCI; Obsolescence; Product Design

Permission to make digital or hard copies of part or all of this work for personal or classroom use is granted without fee provided that copies are not made or distributed for profit or commercial advantage and that copies bear this notice and the full citation on the first page. Copyrights for third-party components of this work must be honored. For all other uses, contact the Owner/Author.

Copyright is held by the owner/author(s).

CHI'15 Extended Abstracts, Apr 18-23 2015, Seoul, Republic of Korea ACM 978-1-4503-3146-3/15/04

http://dx.doi.org/10.1145/2702613.2702621

\section{ACM Classification Keywords}

H.5.m. Information interfaces and presentation (e.g., $\mathrm{HCI}$ ): Miscellaneous.

\section{Research Situation}

My PhD program is a doctorate of informatics at the Department of Informatics at the University of Zurich, for which I have completed all the required coursework, gathered all required ECTS credits, and successfully 
defended my PhD proposal. As I am part of the People and Computing Lab, my research focuses on $\mathrm{HCI}$, and in particular the field of sustainable $\mathrm{HCI}$ ( $\mathrm{SHCI}$ ). My undergraduate studies' background is in computer science, whereas I focused mainly on traditional qualitative $\mathrm{HCI}$ research during my PhD. I am in my fourth year and expect to finish in early 2016.

The completed parts of my PhD research entail theoretical foundations, such as investigating issues regarding environmental sustainability in the domain of consumer electronics through an interview study (unpublished), a literature review of obsolescencerelated research in SHCI [7], and a study of applying a theoretical framework to design practice (currently in submission at $\mathrm{CHI} 2015$ ). In the remainder of my PhD research, I aim to develop systems to support the transfer of theoretical frameworks from SHCI to product designers outside of the field of SHCI and contribute to the core idea of Sustainable Interaction Design [1]. The Doctoral Consortium would be a great opportunity to discuss and inform this last step in my research and share insights I have gathered so far in the process.

\section{Context and Motivation}

The obsolescence of consumer electronics is a major threat to environmental sustainability due to the amount of electronic waste it produces (e.g., [5][12]). The field of $\mathrm{HCI}$, and in particular the related field Ubiquitous Computing, has contributed to the problem with its rapid technological development and thus has a particular responsibility to address those issues. Research in SHCI has started developing theoretical frameworks that offer solutions (e.g., [3][6]) but those have not yet created any impact on product design practice on a larger scale. In my research, I seek to bring one of those established theoretical frameworks, the Attachment Framework [6], to product designers to address those issues, increasing the impact of sustainable HCI research, and establish a set of guidelines for how to communicate theoretical frameworks to practitioners.

\section{Background and Related Work}

The tendency of HCI to produce theoretical frameworks that are rarely put to practice is not a new issue, but has been brought up frequently in the past (e.g.,

[9][10]). This theory-practice gap was observed in the specific domain of SHCI as well [2].

There are a few examples of works that made attempts of bridging this gap. However, those were either case studies with no formal evaluation (e.g., [4]) or short proof-of-concept design exercises (e.g., [3]) rather than in-depth investigations whose primary focus was on assessing the value of those theoretical frameworks for the design process by employing an empirical evaluation method.

The theory-practice gap is particularly apparent within the problem domain of obsolescence, where there has been a variety of theoretical contributions (e.g., [3][6]) but very little insight as to how to apply this to practice. I published a review of approaches to obsolescence from the field of SHCI as a book chapter [7], which was also presented at the ICT4S conference, pointing out the need to investigate on how we bring those solutions to practice. 


\section{Statement of the Problem, Goal, Methods} The main goal of my thesis is to address issues of obsolescence by developing tools that support the design practice of product designers by incorporating existing SHCI frameworks into their design process. In order to achieve this goal, I am addressing the following two research questions:

RQ1: How can an existing sustainable design frameworks be leveraged to provide assistance in the design process of consumer electronics?

To answer this research question, I took one established and empirically developed framework from sustainable HCI - the Attachment Framework [6] - and conducted a study to assess its value for and applicability to the product design process. A group of 14 designers was asked to design a tablet computer that encourages longer use, whereas only half the designers received the Attachment Framework as additional help. The 40 resulting designs were evaluated by ten design experts as well as three experts of the Attachment Framework (affiliated with the project). From this study, I gained valuable insights as to how to apply a theoretical framework from sustainable $\mathrm{HCI}$ to the design process and communicate it to practitioners outside of the field. This contributed to inform my second research question:

\section{RQ2: How can the Attachment Framework be integrated into tools for designing consumer electronics, and what effect does this have on the design process and design outcomes?}

Based on the insights from the first study, I plan on developing a suite of tools that support designers during the ideation stage of the design process while incorporating the Attachment Framework into those tools. One example is a system that allows for designers to sort their background research into a design space, with dimensions based on the design brief instructions as well also attachment-based criteria. Another tool is an app that provides prompts and examples of attachment-inspired design in the brainstorming process. For the evaluation, I plan on giving those tools to designers along with a design task similar to that of the first study and ask them to use those tools in their design process. I intend to gather qualitative data to answer my research question, by observing the designers (in particular the brainstorming process), interview designers about their experience using those tools, and evaluate the resulting designs based on their quality both in terms of general design criteria as well as their potential for encouraging longer use.

\section{Dissertation Status}

Insights from the first part of my research yielded a variety of findings - such as the significance of the target audience, the specific details of the design process, as well as best practices of communicating frameworks. Those findings were presented at the $\mathrm{CHI}$ 2014 sustainability workshop [8]. A more detailed indepth report on the study findings and the challenges are currently in submission at CHI 2015 as a full paper. While this part of my thesis is not written yet, most of it exists already in the form of notes or prior written submissions (e.g., [7][8]) and reports, and I have a clear outline for my entire thesis.

I am currently in the beginning of my last research step, which is to develop tools that support the product 
design ideation process, and expect to finish my PhD in early 2016. At the time of the Doctoral Consortium, I expect to have those tools at a high level of maturity and be able to report on results from first preliminary evaluations. I hope to get assistance in finishing those tools and the final evaluation for my thesis. The evaluation of research goals in sustainable HCI does not follow a generic procedure but varies depending on the specific goals that are being pursued, as "we have yet to develop a vigorous discourse of sustainability evaluation" [11]. Therefore, I consider this one of the most challenging steps in my research, but also one with the largest potential for contributions to the research community.

\section{Expected Contributions}

The major contribution of my thesis will be a template for sustainable HCI research - or potentially even HCI as a larger audience - as to how researchers can communicate theoretical frameworks to design practitioners, increasing the impact of our research. This addresses frequently mentioned concerns (e.g. [9][10]) of bridging the gap between theory and practice, as well as offers crossings between different research fields. On a smaller scope, my PhD thesis aims to provide first steps to addressing the problem of obsolescence by implementing the core idea of Sustainable Interaction Design [1], making sustainable design a central aspect of the product design process.

\section{References}

[1] Blevis, E. Sustainable interaction design: invention \& disposal, renewal \& reuse. In Proc. CHI 2007.

[2] DiSalvo, C., Sengers, P., and Brynjarsdóttir, $H$. Mapping the landscape of SHCI. In Proc. CHI 2010
[3] Gegenbauer, S. and Huang, E.M. Inspiring the design of longer-lived electronics through an

understanding of personal attachment. In Proc. DIS 2012.

[4] Grosse-Hering, B., Mason, J., Aliakseyeu, D., Bakker, C., and Desmet, P. Slow Design for Meaningful Interactions. In Proc. CHI 2013.

[5] Huang, E.M. and Truong, K.N. Breaking the disposable technology paradigm. In Proc. CHI 2008.

[6] Odom, W., Pierce, J., Stolterman, E., and Blevis, E. Understanding why we preserve some things and discard others in the context of interaction design. In Proc. CHI 2009.

[7] Remy, C. and Huang, E.M. Addressing the

Obsolescence of End-User Devices: Approaches from the Field of Sustainable HCI. In ICT Innovations for Sustainability, 474. Advances in Intelligent Systems and Computing 310. Switzerland: Springer International Publishing, 2015.

[8] Remy, C. and Huang, E.M. Tailoring Sustainable HCI Design Knowledge to Design Practice. Position paper in A SIGCHI HCI \& Sustainability community workshop at CHI 2014.

[9] Roedl, D.J. and Stolterman, E. Design Research at $\mathrm{CHI}$ and Its Applicability to Design Practice. In Proc. CHI 2013.

[10] Rogers, Y. New theoretical approaches for humancomputer interaction. Annual Review of Information Science and Technology 38, 1 (2004).

[11] Silberman, M.S., Nathan, L., Knowles, B., Bendor, R., Clear, A., Håkansson, M., Dillahunt, T., and Mankoff, J. Next steps for sustainable HCI. interactions 21, 5 (2014).

[12] Woolley, M. Choreographing obsolescence ecodesign: the pleasure/dissatisfaction cycle. In Proc DPPI 2003. 